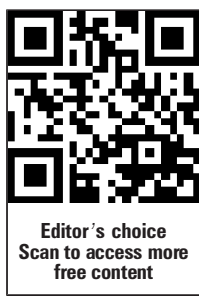

'Department of Psychology, San Diego State University, San Diego, California, USA

${ }^{2} J o i n t$ Doctoral Program in Clinical Psychology, San Diego

State University/University of California, San Diego, California, USA

${ }^{3}$ Graduate School of Public Health, San Diego State University, San Diego, California, USA

${ }^{4}$ San Diego State University Research Foundation, San Diego, California, USA ${ }^{5}$ Joint Doctoral Program in Health Behavior Research, San Diego State

University/University of California, San Diego, California, USA

${ }^{6}$ Department of Chemistry, San Diego State University, San Diego, California, USA

\section{Correspondence to} Dr Georg E Matt, Department of Psychology, San Diego State University, San Diego, CA 92182-4611, USA:

gmatt@sciences.sdsu.edu

Received 13 September 2011 Accepted 18 January 2012

Published Online First

15 February 2012

\title{
Towards smoke-free rental cars: an evaluation of voluntary smoking restrictions in California
}

\author{
Georg E Matt, ${ }^{1}$ Addie L Fortmann, ${ }^{2}$ Penelope J E Quintana, ${ }^{3}$ Joy M Zakarian, ${ }^{4}$ \\ Romina A Romero, ${ }^{5}$ Dale A Chatfield, ${ }^{6}$ Eunha Hoh, ${ }^{3}$ Melbourne F Hovell ${ }^{3}$
}

\section{ABSTRACT}

Introduction Some car rental companies in California and other states in the USA have established non-smoking policies for their vehicles. This study examined the effectiveness of these policies in maintaining smoke-free rental cars.

Methods A stratified random sample of 250 cars (non-smoker, smoker and unknown designation) was examined in San Diego County, California, USA. Dust, surfaces and the air of each vehicle cabin were sampled and analysed for residual tobacco smoke pollutants (also known as thirdhand smoke (THS)), and each car was inspected for visual and olfactory signs of tobacco use. Customer service representatives were informally interviewed about smoking policies.

Findings $A$ majority of putative non-smoker cars had nicotine in dust, on surfaces, in air and other signs of tobacco use. Independent of a car's smoking status, older and higher mileage cars had higher levels of THS pollution in dust and on surfaces ( $p<0.05)$, indicating that pollutants accumulated over time. Compared with smoker cars, non-smoker cars had lower levels of nicotine on surfaces $(p<0.01)$ and in dust $(p<0.05)$ and lower levels of nicotine $(p<0.05)$ and 3-ethynylpyridine $(p<0.05)$ in the air. Non-smoking signage in cars was associated with lower levels of THS pollutants in dust and air $(p<0.05)$. Conclusions Existing policies and practices were successful in lowering THS pollution levels in non-smoker cars compared with smoker cars. However, policies failed in providing smoke-free rental cars; THS levels were not as low as those found in private cars of non-smokers with in-car smoking bans. Major obstacles include inconsistent communication with customers and the lack of routine monitoring and enforcement strategies. Strengthening policies and their implementation would allow car rental companies to reduce costs, better serve their customers and make a constructive contribution to tobacco control efforts.

\section{INTRODUCTION}

The cabins of passenger cars are potentially important microenvironments for exposure to tobacco smoke pollutants. Smoking cigarettes in the small enclosed space of a car cabin can lead to high levels of secondhand smoke (SHS) in the air and to SHS exposure among passengers. ${ }^{1-5}$ In addition, car interiors provide relatively large surface areas with materials that may absorb and trap tobacco smoke pollutants (eg, upholstery, carpets, ceiling liners, air ventilation systems). As such, car cabins are particularly susceptible to becoming reservoirs of residual tobacco smoke pollutants, also known as thirdhand smoke $\left(\mathrm{THS}^{6}\right)$.
Research conducted in the laboratory and the field has demonstrated the presence of THS in the private cars of smokers. Matt et $\mathrm{al}^{7}$ and Fortmann et $a l^{8}$ found in used private cars offered for sale, nicotine levels in dust, on surfaces and in the air of smokers' cars were correlated with the number of cigarettes smoked in the car by the primary driver. Nicotine levels were elevated even if smokers reported in-car smoking bans and reportedly refrained from smoking in their cars. Sleiman et al ${ }^{9}$ demonstrated that nicotine on surfaces presents a hazard because it reacts with ambient nitrous acids to form novel and potent carcinogens that are not present in freshly emitted mainstream smoke (eg, 1-(N-methyl-N-nitrosamino)-1-(3-pyridinyl)-4butanal, 4-(methylnitrosamino)-1-(3-pyridinyl)-1butanone and $\mathrm{N}$-nitrosonornicotine). In addition, Sleiman et al ${ }^{10}$ showed that ozone reacts with SHS to generate ultrafine particles $(<100 \mathrm{~nm})$ and a range of potentially toxic carcinogenic constituents (eg, acrolein, fluoranthene N-nitrosonicotine).

Cars are also important environments for tobacco control from a psychological perspective because they provide a sense of privacy, isolation and protection. Most car trips in the USA involve a single occupant, ${ }^{11}$ creating the impression that smoking alone in a car does not expose others to tobacco smoke pollutants. Because of increased smoking restrictions in the workplace, public places and private homes, cars can become private spaces that Martin et $a l^{12}$ and others ${ }^{13}$ have termed a 'smoker's sanctuary from non-smoking environments'. When an individual routinely smokes in a car, the vehicle becomes a cue that triggers a smoker to light up in this 'protected' environment. ${ }^{14} 15$ Not surprisingly, smoking bans in smokers' cars are less common than in their homes. ${ }^{16-19}$

In contrast to privately owned cars, rental cars are the property of private businesses and are occupied by a number of different drivers and passengers over time. Rental cars are not subject to public smoking bans that are in effect for airplanes, public buildings, public transportation, bars or restaurants. However, in a society where social norms about tobacco use are changing towards smoke-free indoor environments, businesses may benefit by adapting to their customers' changing preference for smoke-free environments. This is what has occurred in California where over the past 2 decades, overall smoking prevalence declined from $25 \%$ (1984) to 13\% (2009), almost all smokers (98\%) and non-smokers (97\%) in 2008 worked in completely smoke-free environments, $81 \%$ of non-smokers and 59\% of smokers in 2008 lived in homes with total smoking bans, and where some 
municipalities have established local smoking bans in outdoor environments such as parks and beaches. ${ }^{20}$

Following significant changes in social norms, many rental car companies in California have adopted voluntary smoking policies intended to provide customers with smoke-free cars. These policies include offering customers the choice to rent nonsmoker and smoker cars or declaring all fleet vehicles nonsmoking. Most recently, Avis/Budget in 2009 and Dollar/Thrifty in 2011 announced that they had adopted strict nationwide smoking restrictions and will charge a penalty of up to US $\$ 250$ for violations. ${ }^{21} 22$

Creating smoking bans alone, however, may not be enough to create smoke-free environments. For smoking bans to be successful, they have to be well implemented. ${ }^{23}$ This includes communicating new policies to customers, training employees, monitoring implementation and compliance and enforcing consequences of violations. Effective implementation of new smoking restrictions is especially important in the competitive service industry where the customer is king and communicating and enforcing smoking restrictions may conflict with profit goals. If smoking restrictions for rental cars are ineffective, the high turnover of rental cars may create tobacco-polluted vehicles over a short period of time. For instance, given a smoking prevalence of $15 \%$ and assuming that smokers and non-smokers make similar rental car choices, the cumulative binomial probability that one or more renters of a given car are smokers is $80 \%$ after 10 rentals, $90 \%$ after 14 rentals and $99 \%$ after 28 rentals. That is, within a few months after a new car has been added to a rental fleet, it may become polluted with THS if voluntary policies are unsuccessful in preventing renters from smoking in the cars.

No research is currently available on the success of voluntary smoking restrictions in creating smoke-free rental cars. This study was designed to evaluate the effectiveness of existing policies and practices for achieving a car cabin free of tobacco smoke pollutants. This study examined rental cars of random samples of branch offices of major national and local rental car companies in southern California to examine the effectiveness of smoking policies in maintaining smoke-free rental cars. Specifically, we investigated whether (1) vehicles rented as designated non-smoker cars were free of tobacco smoke pollutants, (2) vehicles rented without indicating a smoking or non-smoking preference (ie, 'unknown' designation) demonstrated different levels of tobacco smoke pollutants than smoker or non-smoker cars, (3) certain characteristics of cars make them more or less likely to be polluted with tobacco smoke and (4) different areas inside a car vary in level of THS pollutants.

\section{METHODS}

\section{Sample of rental cars}

A stratified random sample of 250 rental cars was selected from national and local car rental company branches in San Diego
County, California, USA (ie, 619 and 858 telephone area codes). Companies were classified as 'national' if they had branches in multiple states (in addition to California); seven of the companies had offices in every state of the USA and one company had offices in 28 states. Although we are referring to these companies as 'national', all of these companies have a multinational scope with branches in other North American and European countries. A majority of these companies also had branches in Central and South America, Australia and New Zealand, Africa, the Middle East and Central and East Asia. Local companies were defined as companies with offices only in Southern California. Internet and telephone book searches yielded a total of 99 national branch offices (representing six companies and eight brands: Avis, Budget, Dollar/Thrifty, Enterprise, Hertz and National/Alamo) and 34 local company offices. Research assistants updated the company list quarterly to capture newly opened branches and delete closed branches. Table 1 describes mileage, age and cabin volume of rental cars by smoking designation (non-smoker, unknown, smoker) and company (national vs local).

\section{Procedures}

Research assistants posing as customers (confederates) called car rental companies to reserve the following types of cars: non-smoker cars ("I would like to make a reservation for a nonsmoker car-a car in which smoking is not allowed"; $\mathrm{N}=100$ ), smoker cars ("I would like to make a reservation for a smoker car-a car in which smoking is allowed"; $\mathrm{N}=50$ ) and unknown smoking designation cars (no smoking preference specified by the confederate upon reservation; $N=100$ ). When the requested non-smoker and smoker cars were picked up, the confederate confirmed with the customer service representative that the car was indeed a non-smoker car or that they were allowed to smoke in the car. Each car was rented for a $24 \mathrm{~h}$ period, during which research assistants examined its interior for signs of previous tobacco use and recorded information about the car specifications. Dust, surface wipe and air samples were also collected. Upon car return, the confederate conducted a semistandardised exit interview with a customer service representative about the company's smoking policy.

\section{Measures \\ Environmental measures \\ Air nicotine and 3-ethenylpyridine}

Air samples were collected in the car's interior for at least $13 \mathrm{~h}$ with a sorbent tube (SKC West 226-93) connected to a sampling pump (SKC Airchek Model 224). Actual sampling time ranged from 13.4 to $18.1 \mathrm{~h}$. Pumps were calibrated to 1.5 LPM before and after use, and samples where pump flow rates changed by $>10 \%$ were discarded. Tubes were transported, cooled and stored at $-20^{\circ} \mathrm{C}$ until extraction, when contents were removed, spiked with internal deuterated standard (3EP-d4 (3-vinylpyridine-d4;

Table 1 Median mileage, age, and cabin volumes of cars rented from local and national rental companies

\begin{tabular}{|c|c|c|c|c|c|c|}
\hline \multirow[b]{3}{*}{ Car characteristics } & \multicolumn{6}{|c|}{ Car reservation and pickup: type of car requested by confederate } \\
\hline & \multicolumn{2}{|c|}{ Non-smoker } & \multicolumn{2}{|c|}{$\begin{array}{l}\text { No preference stated: } \\
\text { unknown designation }\end{array}$} & \multicolumn{2}{|c|}{ Smoker } \\
\hline & Local & National & Local & National & Local & National \\
\hline Mileage $(1000 \text { miles })^{*}$ & 22.6 & 11.3 & 25.6 & 14.2 & 54.4 & 11.6 \\
\hline Age (years)* & 2.3 & 1.3 & 2.3 & 1.5 & 4.9 & 1.3 \\
\hline Cabin volume $\left(\mathrm{ft}^{3}\right)$ & 97.5 & 97.0 & 99.0 & 96.0 & 94.0 & 101.0 \\
\hline
\end{tabular}


TRC Chemical, North York, Ontario, Canada), deuterated nicotine-pyridinal-d4 (nicotine-d4) (66148-15-0, 69980-24-1; CDN Isotopes, Point-Claire, Quebec, Canada) and extracted in methanol. Samples were analysed by liquid chromatography-mass spectrometry-mass spectrometry (LC-MS-MS) as detailed below. The limit of detection (LOD) varied with sampling time but was approximately $1.5 \mathrm{ng} / \mathrm{m}^{3}$ nicotine and $1 \mathrm{ng} / \mathrm{m}^{3}$ 3-ethenylpyridine (3-EP) for the shortest sample. Field blank values were subtracted from the sample values before reporting results.

\section{Dust nicotine}

A subsample of $\mathrm{N}=70$ cars were randomly selected for dust sampling. Dust samples were collected with a High-VolumeSmall Surface-Sampler (HVS4; CS3, Inc., Bend, Oregon, USA) into Teflon bottles. The headliner and front and back seat upholstery were vacuumed. Analytic methods are described in more detail in Matt et al. ${ }^{24}$ The LOD was approximately $0.2 \mu \mathrm{g}$ nicotine/g dust.

\section{Surface nicotine wipe}

Screened cotton wipes were wetted with $1-2 \mathrm{ml}$ of $1 \%$ ascorbic acid and wiped over a $100 \mathrm{~cm}^{2}$ area on the driver's side dashboard of cars. Wipes were placed in glass phials, transported in coolers and stored at $-20^{\circ} \mathrm{C}$. Analytic methods are described in more detail in Matt et al. ${ }^{24}$ The LOD was approximately $0.1 \mu \mathrm{g}$ nicotine $/ \mathrm{m}^{2}$, and field blanks were subtracted from sample values before reporting results. For a subset of the last 40 cars rented, additional wipe samples were collected on the passenger's side and centre dashboard, driver's and passenger's side panels and the steering wheel and steering column.

\section{Analysis of nicotine and 3-EP by $L C-M S-M S$}

The method of analysis was by LC-MS-MS using electrospray ionisation on a Thermo-Finnigan TSQ Quantum Mass Spectrometer. Istotope dilution MS techniques used 3-EP-d4 and nicotine-d4 to quantify the nicotine and 3-EP concentrations. Analytic methods are described in more detail in Matt et al. ${ }^{24}$

\section{Direct observation}

Upon rental car pickup, research assistants examined rental car company offices for signs communicating non-smoking policies and recorded the number, size and placement of policycommunicating signs. Cars were inspected for no-smoking signs, as well as evidence of previous tobacco use. A 3-point scale was used to indicate the presence of ashes and burn marks ('none', 'a little' or 'a lot'). Two items were created to rate the presence of tobacco odour in the context of other odours (ranging from 'not at all smelly' to 'extremely smelly') and strength of tobacco odour (ranging from 'none' to 'extremely strong'). Both odour ratings correlated significantly with nicotine air and surface levels (all r's 0.33-0.39, p<0.001). All direct observations were independently made by two research assistants; scores were compared and reconciled (if needed). Vehicle, make, model, year and mileage (ie, odometer reading at the time of the rental) were also recorded. Using these vehicle specifications, indoor cabin volume was determined from automobile databases. ${ }^{25}$

\section{Semi-standardised exit interview at branch office}

Information about smoking policies was ascertained from the exit interviews with customer service representatives at branch offices who assisted the confederates with rental car returns. Questions asked about a company's rules about smoking in their cars, methods to check whether rules were followed and consequences when customers violated rules. Policies were classified into one of the four categories: (1) 100\% non-smoking policy: smoking is not permitted in any rental cars; (2) designated smoker and non-smoker cars available for rent; (3) the company has no policy regarding smoking in their rental cars and (4) the employee is unsure of company policy.

\section{Analyses}

Statistical analyses were performed using Stata IC V.11. ${ }^{26}$ To control for non-normal distributions and heterogeneous error variances, we applied logarithmic transformations to all quantitative response variables and report geometric means, medians and quartiles. Tobit regression analyses for left-censored data (ie, nicotine and 3-EP levels below the level of detection) were used to test hypotheses about differences in dust, surface and air contamination between non-smoker and smoker cars and between cars rented from national and local companies. The type I error rate was set at $\alpha=0.05$, and hypotheses were tested in a non-directional (two-tailed) fashion. Tukey HSD method was used to protect the type I error when conducting multiple pairwise comparisons. $^{27}$

\section{RESULTS}

\section{Smoking policies of rental car company}

Two hundred and fifty cars were rented from a total of 27 local and 67 national branch offices; 17 local and 39 national offices were visited more than once (range $=2-11$ visits). Data collected during each car return interview are presented in table 2 . Notably, we were able to request and rent 13 'smoker' cars from companies reporting a $100 \%$ no-smoking policy. We were able to request and rent eight 'non-smoker' cars from companies whose customer service representative was unsure of the policy or reported that the company has no smoking policy.

\section{Communicating smoking policies}

When making reservations for 100 cars for which we did not indicate a preference for a smoker or non-smoker car, only one

Table 2 Smoking policy information reported by the rental car company employees when non-smoker, unknown and smoker cars were returned

\begin{tabular}{|c|c|c|c|c|c|c|}
\hline \multirow{3}{*}{$\begin{array}{l}\text { Car return: employee's description } \\
\text { of smoking policy }\end{array}$} & \multicolumn{6}{|c|}{ Car reservation and pickup: type of car requested by confederate } \\
\hline & \multicolumn{2}{|l|}{ Non-smoker } & \multicolumn{2}{|c|}{$\begin{array}{l}\text { No preference stated: unknown } \\
\text { designation }\end{array}$} & \multicolumn{2}{|l|}{ Smoker } \\
\hline & Local, N (\%)† & National, $\mathbf{N}(\%) \dagger$ & Local, N (\%)† & National, $\mathbf{N}(\%) \dagger$ & Local, N (\%)† & National, $\mathbf{N}(\%) \dagger$ \\
\hline $100 \%$ smoke-free cars & $20(80)$ & $38(84)$ & $18(67)$ & $39(83)$ & $3(28)$ & $10(42)$ \\
\hline Smoker and Non-smoker cars & $1(4)$ & $3(7)$ & $0(0)$ & $5(11)$ & $4(36)$ & $12(50)$ \\
\hline Unsure of policy & $2(8)$ & $2(4)$ & $0(0)$ & $1(2)$ & 0 & 0 \\
\hline
\end{tabular}

* Reasons for not conducting interview upon car return included time constraints or interview had already been conducted with same employee during a prior rental at this branch.

†Percentage of completed interviews. 
Table 3 Communicating smoking policies

\begin{tabular}{|c|c|c|c|c|c|c|}
\hline \multirow[b]{3}{*}{ Communicating smoking policies } & \multicolumn{6}{|c|}{ Car reservation and pickup: type of car requested by confederate } \\
\hline & \multicolumn{2}{|l|}{ Non-smoker } & \multicolumn{2}{|c|}{$\begin{array}{l}\text { No preference stated: unknown } \\
\text { designation }\end{array}$} & \multicolumn{2}{|l|}{ Smoker } \\
\hline & Local, $\mathbf{N}(\%)$ & National, N (\%) & Local, N (\%) & National, N (\%) & Local, N (\%) & National, N (\%) \\
\hline \multicolumn{7}{|l|}{ Rental contract } \\
\hline Smoking allowed in car & $0(0)$ & $0(0)$ & $0(0)$ & $0(0)$ & $0(0)$ & $0(0)$ \\
\hline Smoking prohibited in car & $13(26)$ & $22(44)$ & $12(24)$ & $18(36)$ & $2(8)$ & $0(0)$ \\
\hline No mention of smoking & $37(74)$ & $28(56)$ & $38(76)$ & $32(64)$ & $23(92)$ & $25(100)$ \\
\hline Rental office & $9(22)$ & $0(0)$ & $6(15)$ & $0(0)$ & $1(5)$ & $0(0)$ \\
\hline Front of car & $8(16)$ & $7(14)$ & $9(18)$ & $7(15)$ & $2(8)$ & $6(24)$ \\
\hline Back of car & $0(0)$ & $1(2)$ & $0(0)$ & $0(0)$ & $0(0)$ & $0(0)$ \\
\hline Key ring & $1(2)$ & $15(31)$ & $2(4)$ & $12(25)$ & $1(4)$ & $7(28)$ \\
\hline Anywhere in car & $8(16)$ & $21(43)$ & $11(22)$ & $16(34)$ & $3(12)$ & $10(40)$ \\
\hline
\end{tabular}

customer service representative brought up the issue of tobacco use, asking whether the confederate intended to smoke in the car. Table 3 shows how customers were informed of smoking policies through a statement in the rental contract or signage in the rental office or car.

\section{Visual and olfactory evidence}

Table 4 shows the percentage of rental cars with visual and olfactory evidence of tobacco use. Based on the overall evidence (ie, any sign of ash, burn marks or odour), a majority of cars from local $(69 \%-90 \%)$ and national $(56 \%-67 \%)$ companies appeared to have been smoked in, regardless of their putative designation as non-smoker or smoker cars.

\section{THS pollution of rental cars}

Table 5 shows nicotine and 3-EP levels found in dust, air and on surfaces of non-smoker and smoker cars and of cars with unknown designation. Based on nicotine thresholds developed for private used cars of non-smokers with car smoking bans, ${ }^{7}$ $52 \%-75 \%$ of putative non-smokers cars rented from local companies and $44 \%-54 \%$ of those rented from national companies had nicotine levels in dust, air or surfaces above nonsmoker thresholds. If non-smoker preference was not requested, the corresponding percentages were $46 \%-66 \%$ and $57 \%-67 \%$, respectively.

Dust nicotine

Tobit regression analyses indicated that older cars had significantly higher levels $(p<0.05)$ of dust nicotine levels than newer cars, independent of smoking designation and local or national company status. This suggests that THS pollutants accumulate over time in dust that is trapped in carpets, upholstery and other fabrics. In addition to the age effect, smoker cars had significantly higher levels of dust nicotine than non-smoker cars $(p<0.05)$ but not cars of unknown designation $(p>0.30)$. Controlling for age of cars, THS pollution of cars from local and national companies did not significantly differ $(p>0.40)$. Independent of age and smoking designation, signage informing passengers of smoking bans was associated with statistically significant lower THS levels $(p<0.005)$. This suggests that renters comply with signage to refrain from smoking. The overall Tobit model of showed an acceptable fit with smoking designations, age and signage as explanatory variables $\left(\chi^{2}(4)=\right.$ 22.18, $\mathrm{p}<0.001)$.

\section{Surface nicotine}

Analysis with Tobit regression models for surface nicotine levels on the dashboard of rental cars demonstrated similar findings to those for dust nicotine levels. Consistent with the accumulation of THS pollutants, older cars had significantly higher levels $(p=0.001)$, independent of smoking designation of cars and local or national rental car company. Smoker cars had significantly higher levels of surface nicotine than non-smoker cars $(p=0.001)$ but not undesignated cars $(p=0.26)$. Controlling for age of cars, THS pollution of cars from local and national companies did not significantly differ $(p=0.50)$. Independent of age and smoking designation, signage informing passengers of smoking bans was associated with lower THS levels $(p=0.063)$. The overall Tobit model showed an acceptable fit with smoking designations, age and signage as explanatory variables $\left(\chi^{2}(4)=29.56, p<0.001\right)$.

\section{Air nicotine and 3-EP}

In contrast to our findings for dust and surfaces, air nicotine and air 3-EP levels did not increase with the age or mileage of a car.

Table 4 Signs of tobacco use in rental cars

\begin{tabular}{|c|c|c|c|c|c|c|}
\hline \multirow[b]{3}{*}{ Signs of tobacco use } & \multicolumn{6}{|c|}{ Car reservation and pickup: type of car requested by confederate. } \\
\hline & \multicolumn{2}{|l|}{ Non-smoker } & \multicolumn{2}{|c|}{$\begin{array}{l}\text { No preference stated: unknown } \\
\text { designation }\end{array}$} & \multicolumn{2}{|l|}{ Smoker } \\
\hline & Local, N (\%) & National, $\mathbf{N}(\%)$ & Local, N (\%) & National, $\mathbf{N}(\%)$ & Local, $\mathbf{N}(\%)$ & National, N (\%) \\
\hline Ash in ashtrays* & $9(64)$ & $8(57)$ & $14(67)$ & $4(29)$ & $8(80)$ & $3(50)$ \\
\hline Ash anywhere in car & $19(45)$ & $14(34)$ & $14(58)$ & $18(43)$ & $15(71)$ & $13(62)$ \\
\hline Used lighters $†$ & $12(30)$ & $7(17)$ & $23(44)$ & $11(28)$ & $12(60)$ & $5(28)$ \\
\hline Moderate/strong odour & $5(11)$ & $4(9)$ & $7(17)$ & $4(10)$ & $8(38)$ & 2 (9) \\
\hline Any sign, anywhere in car & $29(69)$ & $23(56)$ & $26(65)$ & $23(56)$ & $19(90)$ & $14(67)$ \\
\hline
\end{tabular}

* Of cars with ashtrays.

†Of cars with lighters. 
Table 5 Thirdhand smoke pollutants in dust, surfaces and in the air of cars rented as non-smoker, smoker and unknown designations

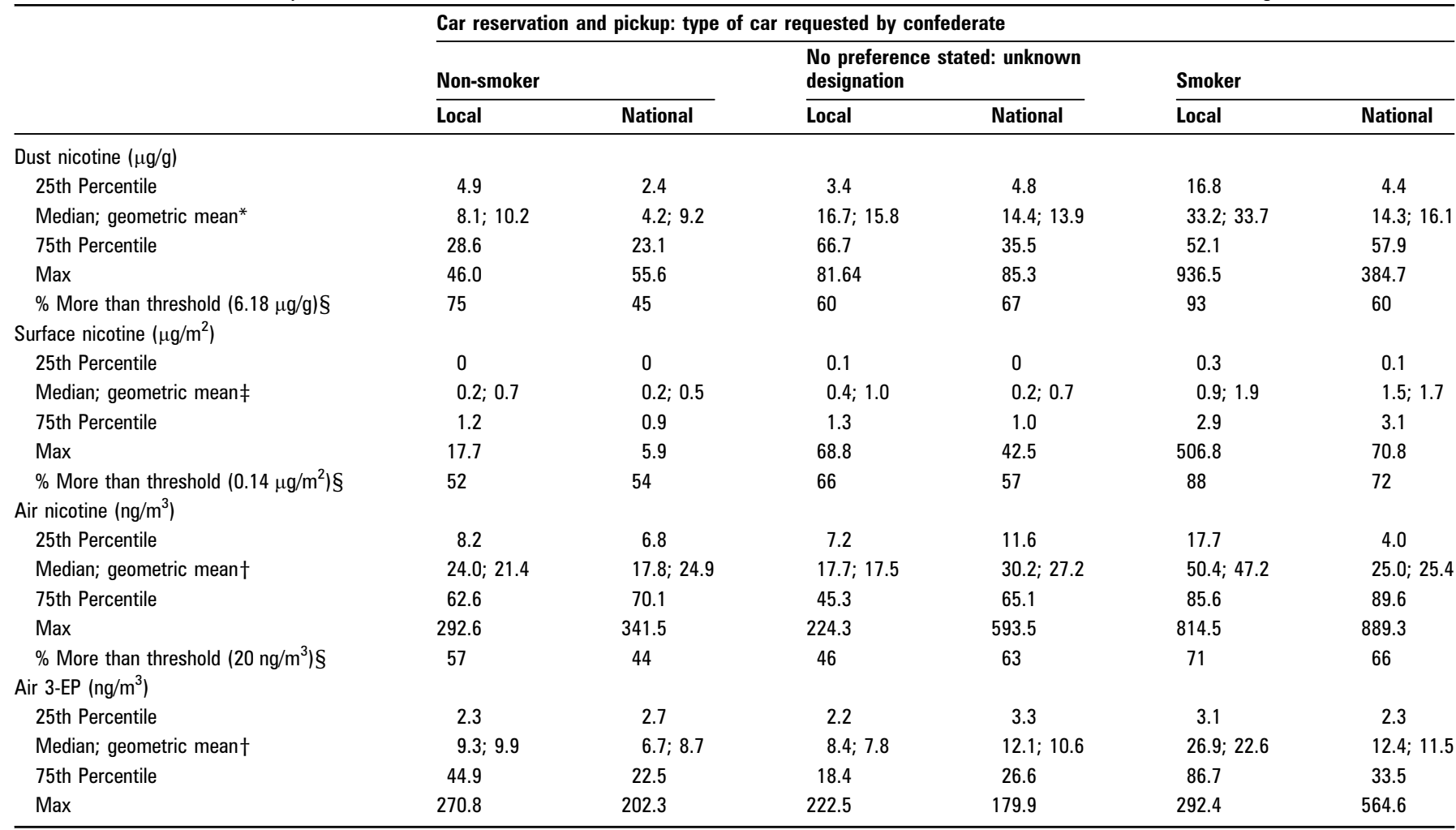

*Pairwise comparison for dust nicotine levels: $p<0.05$ (Tukey HSD) non-smoker versus smoker

†Pairwise comparisons for air nicotine and air 3-EP: are not statistically significant, $\mathrm{p}>0.05$ (Tukey HSD).

$\ddagger$ Pairwise comparisons for surface nicotine: $p<0.05$ (Tukey HSD): non-smoker versus unknown; unknown versus smoker car.

$\S$ Thresholds based on used cars for sale by non-smokers with a car smoking ban.

Similar to dust and surfaces, air nicotine and 3-EP levels were highest in designated smoker cars $(p<0.05)$, and signage for smoking bans inside the car were significantly associated with lower levels of air nicotine $(p=0.03)$ and 3-EP $(p=0.018)$.

Spatial distribution of surface nicotine levels in rental car cabin To better understand the spatial distribution of surface nicotine levels in a car, we sampled seven different areas in the front section of a subset of 16 non-smoker cars, eight smoker cars and 16 cars of unknown designation (see table 6). The most polluted surface in all three types of cars was the top of the steering column, located behind the steering wheel and in front of the driver's legs. The least polluted in all three cars was the steering wheel. Nicotine levels on the dashboard and window panels showed intermediate levels.

Table 6 Spatial distribution of median surface nicotine levels $\left(\mu \mathrm{g} / \mathrm{m}^{2}\right)$ in rental cars

\begin{tabular}{|c|c|c|c|}
\hline \multirow[b]{2}{*}{ Location in car } & \multicolumn{3}{|c|}{$\begin{array}{l}\text { Car reservation and pickup: type of car requested by } \\
\text { confederate }\end{array}$} \\
\hline & $\begin{array}{l}\text { Non-smoker, } \\
\mathrm{N}=16\end{array}$ & $\begin{array}{l}\text { No preference } \\
\text { stated: unknown } \\
\text { designation, } N=16\end{array}$ & $\begin{array}{l}\text { Smoker, } \\
\mathrm{N}=8\end{array}$ \\
\hline Dashboard driver & 0.44 & 0.18 & 0.64 \\
\hline Dashboard centre & 0.49 & 0.13 & 0.54 \\
\hline Dashboard passenger & 0.32 & 0.19 & 0.59 \\
\hline Window panel driver & 0.22 & 0.07 & 0.33 \\
\hline Window panel passenger & 0.24 & 0.28 & 0.48 \\
\hline Steering wheel & 0.05 & 0.06 & 0.13 \\
\hline Steering column & 1.18 & 0.99 & 1.03 \\
\hline
\end{tabular}

\section{DISCUSSION}

This study examined the effectiveness of smoking policies and practices of rental car companies aimed at providing their customers with smoke-free cars. Our findings suggest that existing policies and practices largely failed to protect the rental cars sampled in this study from accumulating THS pollutants. Despite explicitly requesting and confirming a non-smoker rental car, more than $60 \%$ of putative non-smoker cars had been smoked in previously, based on visible physical evidence of tobacco use (eg, ash, lighter use, burn marks) or moderate to strong tobacco odour. Objective measures of THS confirmed this finding: $50 \%$ of non-smoker cars rented from national and $75 \%$ of non-smoker cars rented from local companies had nicotine levels in dust and on surfaces above the threshold established for private cars of non-smokers with car smoking bans. The mean levels found in designated non-smoker rental cars were three times higher for dust nicotine and 10 times higher for surface nicotine than those found in private cars of non-smokers with smoking bans. When the confederate did not specifically request a non-smoker car, the prevalence of tobacco use was even higher. Between $60 \%$ and $80 \%$ of the cars with unknown smoking designation showed evidence of prior tobacco use; and mean levels of nicotine in dust and on surfaces were 5-15 times higher than in private cars of non-smokers with smoking bans. Our findings suggest that tobacco smoke pollutants accumulate over time in dust and on surfaces. Regardless of non-smoking or smoking designation, cars with higher mileage showed higher levels of THS in dust and on surfaces but not in the air. This suggests that even when tobacco use in rental cars occurs only occasionally, THS pollutants build up over time on surfaces and in dust. 
Compared with private cars of smokers, ${ }^{7}$ THS levels in the dust of rental cars were similar (median $=15-20 \mu \mathrm{g} / \mathrm{g}$ ), whereas THS levels on dashboards were significantly lower. This was likely the case because rental cars were newer (mileage: $20 \mathrm{~K}$ to $40 \mathrm{~K}$ ) than the private cars (mileage: $60 \mathrm{~K}$ to $80 \mathrm{~K}$ ) and because rental cars dashboards are regularly cleaned between rentals. Cleaning patterns may also explain why we found higher levels of THS pollutants on surfaces that are less accessible (ie, top of steering column).

The location of this study has implications for the interpretation of the present findings. Specifically, this study was conducted in San Diego, California (USA), where tobacco use is prohibited in restaurants, bars, on public transportation, in public buildings, schools, hospitals, most workplaces, parks, playgrounds and beaches. However, smoking in private vehicles is prohibited if a child under the age of 18 is present. The smoking prevalence among adult Californians is near 15\%, lower than in most other states in the USA and lower than in many other countries. ${ }^{28}$ We expect that in states and countries with more permissive smoking norms than in California, smoking policies for rental cars and their implementation will be more lenient and THS pollution levels in rental cars will be higher than reported here. We would also predict that in societies with stricter policies and social norms about tobacco use, rental cars will be less polluted with THS. Additional research will be needed to test these hypotheses.

Our study involved 'local' rental car companies with branches only located in Southern California, as well as 'national' companies with branches throughout the USA and in many other countries worldwide. The similarity of findings for local and national companies in San Diego County suggests that potential differences between local and national companies in management, employee training, customers, marketing and rental car models did not affect the propensity of cars to accumulate THS pollutants. Therefore, we suspect that car rental companies with similar policies and practices in other states in the USA and in other countries with equivalent or higher smoking prevalence face similar challenges to keeping designated non-smoker rental cars smoke free.

While existing policies and practices fall short of protecting customers from renting THS-polluted cars, our findings point to important potential sources of this failure. First, non-smoking policies are often not well publicised, making it difficult for a customer to know and understand a company's smoking policy. Second, interactions with company representatives during reservation and car pickup do not make smoking policies a priority unless a customer explicitly requests a smoke-free car. Consequently, non-smokers often do not know that they could have requested a non-smoker car and smokers often do not know that they may not be allowed to smoke in a rental car. Third, few companies placed signage in their offices or rental cars to communicate that smoking is prohibited. However, when policy-communicating signage was displayed (eg, sticker on dashboard, sign on key chain), THS levels were significantly lower than in equivalent cars without such signage. Finally, the process for returning rental cars rarely allows for an immediate, reliable and valid check of whether a customer smoked, and companies do not appear to have an effective way to completely remove THS from a car in which a previous customer may have smoked.

Short of removing and replacing polluted objects, it is currently not known how to extract or neutralise THS compounds embedded in upholstery and adhering to inaccessible surfaces. In fact, some products advertised for 'removing unpleasant odours' are known to worsen the toxicity of some THS components because they contain the oxidant ozone. Instead of changing an odorant compound into a harmless odourless compound, ambient nitrous oxides and ozone may converts nicotine and other SHS compounds to more toxic pollutants. ${ }^{9} 10$ Research is needed to identify effective and cost-efficient strategies to clean and remove THS pollution.

To better protect non-smokers from renting THS-polluted rental cars, customers and rental car companies have important roles to play. First, customers should explicitly ask for a nonsmoker car and check for signs of tobacco use before they drive off in a rental car. Second, car rental companies must make their smoking policies transparent and explicit during the reservation and check-in process. In addition, signage in the rental car office, on car key rings and in the vehicle provides inexpensive and effective reminders to refrain from smoking in a vehicle. Finally, rental car companies would benefit from developing a reliable and valid process to monitor and enforce compliance with their policy. In well-publicised efforts, Avis/Budget in 2009 and Dollar/Thrifty in 2011 announced that they had adopted strict nationwide non-smoking policies and will charge a penalty of up to US\$250 for violations. ${ }^{21} 22$ While this is an important step in the right direction, the online reservation pages at Avis/Budget and Dollar/Thrifty in June 2011 do not mention any fines and do not indicate how compliance with their non-smoking policies is monitored. In the present study, Avis, Dollar and Thrifty mentioned the ' $100 \%$ smoke-free' policy in the fine print under terms and conditions, a section not commonly studied in a great detail by rental car customers. Avis and Budget recently increased the prominence of their smoking policy, informing customers on their reservation website with a non-smoking symbol that their fleet is $100 \%$ smoke free in the USA and Canada.

Many of the national car rental companies operating in the USA and examined in this study are global service companies with branches and affiliates in many other countries in the Americas, Africa, Asia, Australia and Europe. Because of their international presence and the importance of building global brand identities, global service companies can potentially play a significant role in promoting tobacco control efforts by denormalising tobacco use in indoor environments. This could include adopting smoking restrictions in cars, communicating policies to customers, training employees and implementing effective strategies for monitoring compliance. Similar steps already have been taken by several national and international hotel chains (eg, Marriot, Westin, Hyatt) whose non-smoking policies started in the USA and were later adopted by hotels in other countries. ${ }^{29}$

What this paper adds

- This is the first study to examine the effectiveness of smoking policies and practices of rental car companies aimed at providing their customers with smoke-free cars.

- Existing policies and practices largely failed in providing smoke-free rental cars.

- Tobacco smoke pollutants build up over time on surfaces and in dust even when smoking occurs only occasionally.

- Non-smoking signage (eg, sticker in car, sign on key chain) was associated with lower levels of tobacco smoke pollutants. 
Contributors All authors made substantial contributions to (1) the conception and design, acquisition of data or analysis and interpretation of data; (2) drafting the article or revising it critically for important intellectual content and (3) final approval of the version published. GEM, ALF and PJEO are responsible for the overall content as guarantors.

Funding This research was supported by funds from the California Tobacco-Related Disease Research Grants Program Office of the University of California, Grant Number 15RT-0160.

Competing interests None.

Provenance and peer review Not commissioned; externally peer reviewed.

\section{REFERENCES}

1. Offermann FJ, Colfer $\mathrm{R}$, Radzinski $\mathrm{P}$, et al. Exposure to environmental tobacco smoke in an automobile. Indoor Air 2002 - 9th International Conference on Indoor Air Quality and Climate. Rotterdam, the Netherlands, 2002:506-11.

2. Ott W, Klepeis N, Switzer P. Air change rates of motor vehicles and in-vehicle pollutant concentrations from secondhand smoke. J Expo Sci Environ Epidemiol 2008; 18:312-25.

3. Park JH, Spengler JD, Yoon DW, et al. Measurement of air exchange rate of stationary vehicles and estimation of in-vehicle exposure. J Expo Anal Environ Epidemiol 1998;8:65-78.

4. Jones MR, Navas-Acien A, Yuan J, et al. Secondhand tobacco smoke concentrations in motor vehicles: a pilot study. Tob Control 2009;18:399-404.

5. Rees VW, Connolly GN. Measuring air quality to protect children from secondhand smoke in cars. Am J Prev Med 2006;31:363-8.

6. Matt GE, Quintana PJE, Destaillats $\mathrm{H}$, et al. Thirdhand tobacco smoke: emerging evidence and arguments for a multidisciplinary research agenda. Environ Health Perspect 2011;119:1218-26.

7. Matt GE, Quintana PJ, Hovell MF, et al. Residual tobacco smoke pollution in used cars for sale: air, dust, and surfaces. Nicotine Tob Res 2008;10: 1467-75.

8. Fortmann AL, Romero RA, Sklar M, et al. Residual tobacco smoke in used cars: futile efforts and persistent pollutants. Nicotine Tob Res 2010;12:1029-36.

9. Sleiman M, Gundel LA, Pankow JF, et al. Formation of carcinogens indoors by surface-mediated reactions of nicotine with nitrous acid, leading to potential thirdhand smoke hazards. Proc Natl Acad Sci U S A 2010;107 6576-81.

10. Sleiman M, Destaillats H, Smith JD, et al. Secondary organic aerosol formation from ozone-initiated reactions with nicotine and secondhand tobacco smoke. Atmos Environ 2010;44:4191-8.
11. U.S. Department of Transportation. Average vehicle occupancy by mode and person. National Household Travel Survey 2009. Washington DC: Federal Highway Administration, 2009.

12. Martin J, George R, Andrews $\mathrm{K}$, et al. Observed smoking in cars: a method and differences by socioeconomic area. Tob Control 2006;15:409-11.

13. TNS New Zealand. Second-hand Smoking in Homes. Qualitative Research Report Auckland, New Zealand: Health Sponsorship Council and the Quit Group, 2003.

14. Shiffman S, Paty JA, Gwaltney CJ, et al. Immediate antecedents of cigarette smoking: an analysis of unrestricted smoking patterns. J Abnorm Psychol 2004;113:166-71.

15. Shapiro D, Jamner LD, Davydov DM, et al. Situations and moods associated with smoking in everyday life. Psychol Addict Behav 2002;16:342-5.

16. Gilpin EA, Emery SL, Farkas AL, et al. The California Tobacco Control Program: A Decade of Progress, 1989-1999. La Jolla: University of California, San Diego, 2001

17. Gilpin EA, White MM, White VM, et al. Tobacco Control Successes in California: A Focus on Young People, Results from the California Tobacco Surveys, 1990-2002. La Jolla, CA: University of California, San Diego, 2003.

18. Halterman JS, Fagnano M, Conn KM, et al. Do parents of urban children with persistent asthma ban smoking in their homes and cars? Ambul Pediatr 2006;6:115-19.

19. Kegler MC, Malcoe LH. Smoking restrictions in the home and car among rural Native American and white families with young children. Prev Med 2002;35:334-42.

20. Al-Delaimy WK, White MM, Mills AL, et al. Two Decades of the California Tobacco Control Program: California Tobacco Survey, 1990-2008. La Jolla, CA: University of California, San Diego, 2010.

21. Koch W. Budget, Avis ban smoking in cars. USA Today 2009

22. Stewart DR. Dollar Thrifty sets no-smoking policy in rental cars. Tulsa World 2011

23. Callinan JE, Clarke A, Doherty $\mathrm{K}$, et al. Legislative smoking bans for reducing secondhand smoke exposure, smoking prevalence and tobacco consumption. Cochrane Database Syst Rev 2010;(4):CD005992.

24. Matt GE, Quintana PJ, Zakarian JM, et al. When smokers move out and nonsmokers move in: residential thirdhand smoke pollution and exposure. Tob Control 2011;20:e1.

25. Office of Energy Efficiency and Renewable Energy. Find and Compare Cars. Washington DC: US Environmental Protection Agency, 2011.

26. StataCorp. Stata Statistical Software: Release 11. College Station, TX: Stata Corporation, 2010.

27. Maxwell SE, Delaney HD. Designing Experiments and Analyzing Data. 2nd edn. Mahwah, NJ: Lawrence Erlbaum, 2004.

28. Storr CL, Cheng H, Alonso J, et al. Smoking estimates from around the world: data from the first 17 participating countries in the World Mental Health Survey Consortium. Tob Control 2010:19:65-74.

29. Stoller G. More hotels go completely smoke-free. USA Today 2011. 